\title{
iiiBienvenidos al apasionante mundo del emprendimiento educativo!!!! Una experiencia innovadora para plantar la semilla del emprendimiento educativo en los futuros profesores
}

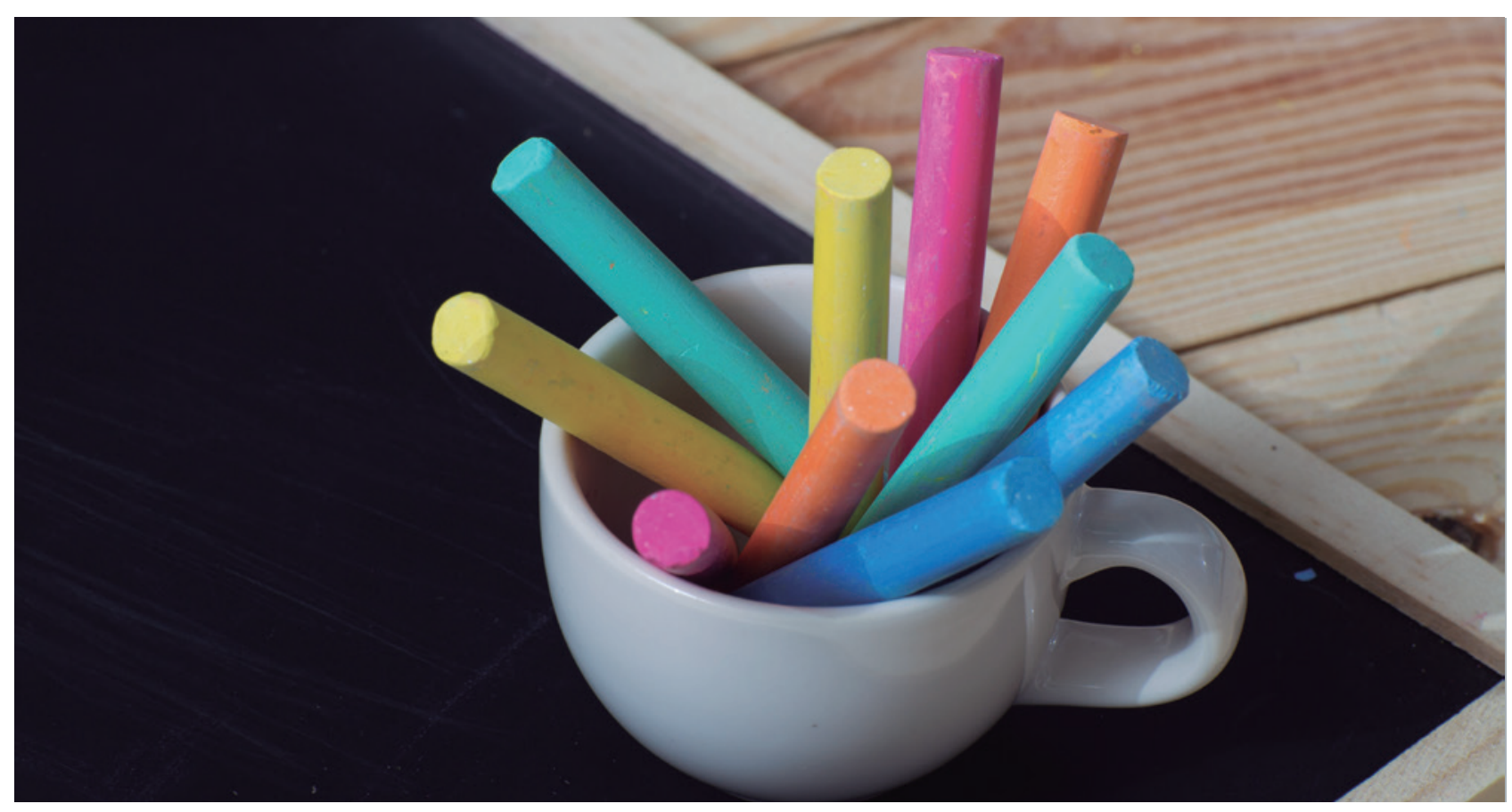

iiiBienvenidos al apasionante mundo del emprendimiento educativo!!! Con este sugestivo reto dio comienzo la asignatura de Autonomía Personal y Salud Infantil durante el curso 2017-18. En este artículo

María Rosa Salas Labayen

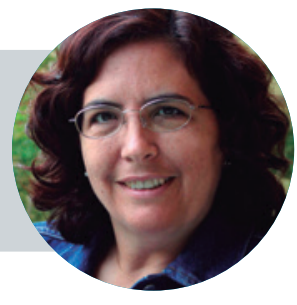

Facultad de Ciencias Humanas y Sociales Universidad Pontificia Comillas rsalas@comillas.edu

se describe la experiencia llevada a cabo

en la mencionada materia con alumnos de

1. er curso de Educación Infantil y del doble

grado de Educación Infantil y Educación

Primaria en la Universidad Pontificia

Comillas. 
Este proyecto de innovación docente surge tras la reflexión, por un lado, sobre la metodología utilizada en años anteriores en la asignatura de Autonomía Personal y Salud Infantil que deben cursar los alumnos de Educación y, por otro, sobre el hecho constatado en las entrevistas de admisión a los estudios de Magisterio de que cuando preguntas a los candidatos cómo se ven profesionalmente dentro de diez años y qué les gustaría estar haciendo, lo habitual es que respondan "dando clase", no siendo habitual que se planteen otras alternativas.

De esta reflexión surgen dos convencimientos. El primero es que se trata de una asignatura básica para los futuros docentes y muy práctica, y que por ello debe ser aprendida de forma más aplicada a como se venía haciendo hasta ese momento. El segundo es que no debemos dejar de lado la actitud emprendedora como competencia profesional relevante en nuestros futuros profesores. Lo complejo de unir estas dos convicciones era cómo hacerlo para que todo ello tuviera sentido pedagógico y sin que la materia perdiera contenido, coherencia ni efectividad. Organizar y pensar todo esto llevó varios meses y aun así habrá que ir matizándolo en cursos posteriores tras el análisis de esta primera experiencia, pero el camino ha comenzado este pasado septiembre...

\section{Empezamos la experiencia...}

El primer día de clase se explica a los alumnos que en esta asignatura se dividirán en grupos estables de trabajo de 6 personas. El objetivo que debían lograr era crear, al final del cuatrimestre, una Escuela Infantil. Cada grupo tendrá a su disposición $2.000 \mathrm{~m}^{2}$, que podrá usar como quiera, aunque siempre ajustándose a la normativa legal correspondiente. Para ello, cada grupo se constituyó como equipo directivo/docente del centro, cuyo director fue nombrado por la profesora de la asignatura entre aquellas personas que mostraron más predisposición a asumir ese rol. Los demás miembros de cada grupo fueron asignados al azar, intentando emular una situación real en la que se

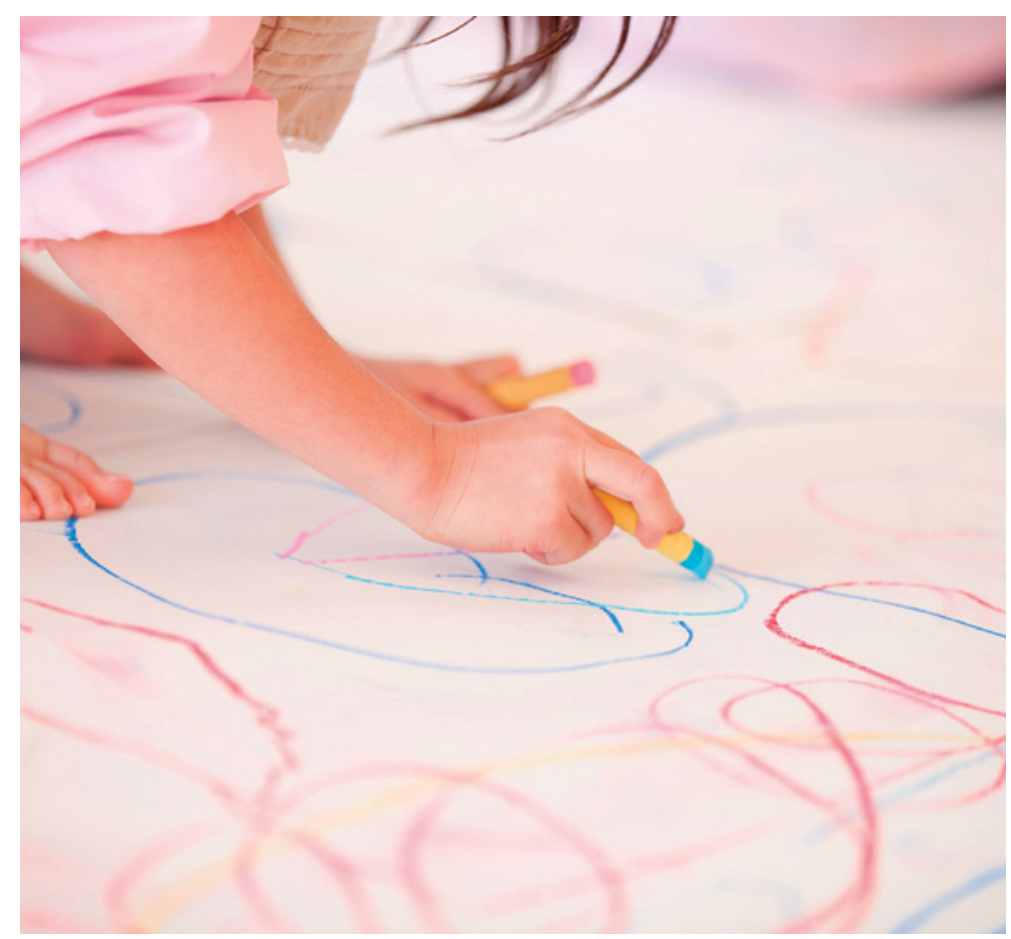

contratan personas que no se conocen entre sí.

En esta experiencia, como en la vida real, el director podrá expulsar a un profesor de su escuela si el trabajo no es el adecuado, siempre y cuando estén de acuerdo al menos 3 personas más del equipo directivo. En este caso, el profesor expulsado no podrá obtener más de un 5 en esta parte de la asignatura y trabajará solo o con otros expulsados (si los hay).

La situación inversa también se contempla y, así, si 4 profesores o más están de acuerdo, podrán expulsar al director, aplicándose los mismos criterios anteriormente descritos. El proceso acabará con el grupo eligiendo a otro director.

Una vez dado este primer paso, se explica a los estudiantes lo que se va a hacer a lo largo del cuatrimestre. El objetivo final es que cada grupo presente un dosier con el proyecto de la escuela y una maqueta. Centrar todo en la creación de una escuela infantil se justifica por tres evidencias: la primera, que tiene más que ver con lo pedagógico, es que a veces los espacios condicionan lo que se puede o no hacer en un espacio concreto; la segunda es que si en algún momento cualquiera de ellos se planteara de verdad crear su propio centro educativo, existe una gran cantidad -y compleja- de normativa que deben considerar y cuyo incumplimiento puede tener consecuencias legales serias; y la tercera 
$\pi$ Ya tenemos el equipo docente.

$\pi$ Ahora hay que empezar a crear nuestra escuela infantil:

$\pi$ Empezaremos por ponerle un nombre.

$\pi \quad$ Luego haremos el plano de nuestra escuela infantil.

$\pi$ Condiciones de inicio:

$\pi$ Escala 1:100 (1 $\mathrm{m}$ en la realidad se representa con $1 \mathrm{~cm}$ en el plano).

$\pi$ Vuestro plano debe incluir TODO aquello que creáis que debe tener una escuela infantil.

त Máxima superficie: $2.000 \mathrm{~m}^{2}$.

$\pi$ Debéis considerar que debe haber, al menos, un aula para 0-1; 1-2; 2-3; 3-4; 4-5; y 5-6 años > total: 6 aulas mínimo.

$\lambda$ Acabaremos con una maqueta a escala 1:50 (50 cm en la realidad se representa con $1 \mathrm{~cm}$ en la maqueta) $>$ cada miembro del equipo aportará a la maqueta su clase + un espacio común.

es que, aunque trabajen en un centro por cuenta ajena, deben ser conscientes de los tres aspectos anteriormente mencionados ya que, al final, gran parte de la responsabilidad de lo que sucede o no sucede en un centro educativo, es compartida por todos los agentes que intervienen.

Una vez sentadas las bases del trabajo, los distintos equipos docentes buscaron un nombre y logo para su escuela, hicieron una estimación de presupuesto (jentre 60.000 y dos millones de euros!, según los grupos) y realizaron el primer boceto del plano de cada centro. En la puesta en común se pusieron de manifiesto grandes diferencias entre los distintos grupos de trabajo:

7 Espacios que no aparecían en ningún plano y que eran necesarios como, por ejemplo, recepción, despacho para la dirección o sala de profesores.

入 Espacios que no aparecían en el plano por desconocimiento de los alumnos como, por ejemplo, la biberonería en los casos de alumnos de menor edad.

$\boldsymbol{7}$ Escuelas infantiles con todo tipo de espacios (patio cubierto y al aire, sala de psicomotricidad, gimnasio, piscina...), aunque a veces les faltaran otros imprescindibles.

$\boldsymbol{7}$ Escuelas en las que solo estaba presente lo más imprescindible y previsible (aulas, baños y poco más).

Para finalizar, se les proporcionó la bibliografía y normativa vigente a nivel nacional y autonómico para que analizasen sus propias propuestas de espacios y las fuesen adaptando a las mismas, teniendo en cuenta que cada uno podría tener requisitos diferentes desde el punto de vista legal, según los alumnos que fueran a ocuparlos.

En esta fase también se les dio información sobre aquellos espacios en los que nadie había pensado y que, sin embargo, debían estar (por ejemplo, almacén de alimentos, de juguetes/material didáctico y de productos de limpieza).

No se proporcionó a los alumnos desde el principio la información normativa, ya que uno de los objetivos era enfrentar sus ideas previas a la realidad para que reflexionasen y valorasen ambas opciones.

\section{Desarrollo de la experiencia}

Durante el resto de la asignatura se fueron analizando cada uno de los temas de la asignatura asociándolos siempre a la creación de los espacios en las distintas Escuelas que posibilitaran su implementación en una hipotética situación real.

Desde esta perspectiva, cada grupo fue diseñando las aulas en función de las necesidades derivadas de las distintas edades de los alumnos (forma de la clase, metros cuadrados, etc.) y de las condiciones exigibles en función de la seguridad y la salud.

También cada equipo docente tuvo que buscar el mobiliario de los distintos espacios de sus respectivas escuelas infantiles. Este aspecto fue importante ya que debe estar adaptado a la edad y actividades propias de cada momento evolutivo, pero también debe cumplir con otras condiciones como la normativa europea de seguridad, ser duradero, resultar atractivo a los alumnos o tener un precio 
PRESUPUESTO

Para un aula de 20 alumnos del grupo de 2-3 años: se adquieren 30 piezas (alguna más para poder reponer): $89 €$

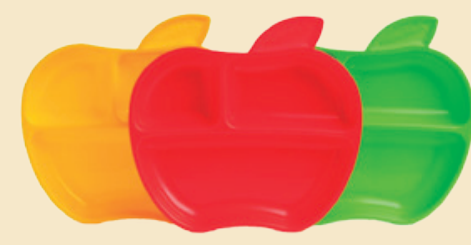

Imagen: Munchkin apple. Amazon.es

\section{VENTAJAS}

$\pi$ Son aptos para uso humano infantil

$\pi$ Son de plástico

$\pi$ No se rompen

त Son baratos: $2,90 €$ por alumno

$\pi$ Su forma está adaptada a su uso por niños pequeños

$\pi$ Colores atractivos

入 Fácil limpieza

$\pi$ Se pueden lavar en lavavajillas

$\pi$ Se pueden apilar, por lo que ocupan poco espacio

$\pi$ Se pueden usar en microondas y lavar en lavavajillas

\section{INCONVENIENTES}

入 Puede que no siempre estén disponibles, por lo que la uniformidad en la vajilla se puede ver afectada

$\pi$ Pueden encontrarse más baratos y con prestaciones similares

$\pi$ No tienen ventosas para que se adhieran a la mesa y evitar que caigan

$\pi$ Para mayores de 3 años las raciones son justas o escasas que lo haga factible de ser adquirido en una hipotética situación real.

Siguiendo el mismo proceso, cada equipo docente tenía que buscar el resto de los elementos que consideraran necesario adquirir, a excepción del material puramente pedagógico, ya que al tratarse de alumnos de $1 .^{\text {er }}$ curso se ha considerado que aún no tenían suficiente formación para ello.

A la hora de seleccionar cada adquisición, debían buscar en diferentes webs y, pensando siempre en los alumnos del aula que tenían asignada, analizar tres aspectos: ventajas del producto elegido, desventajas y presupuesto.

Estos análisis y la selección de materiales se fue haciendo no solo para las aulas, sino también para los aseos (para niños de distintas edades y adultos), comedor, cocina, patio, despachos y salas de reuniones, almacenes, lavandería (si la incluyeron), sala multiuso (si la iban a poner como parte de su escuela), etc.

Especialmente importante por su complejidad y por las posibles consecuencias de no actuar adecuadamente, fue el tema de la alimentación. Existe una normativa muy específica y exigente en este aspecto que debe ser tenida en consideración y que afecta a aspectos en los que ningún alumno hubiera pensado de forma intuitiva.

Para completar este apartado, los alumnos tuvieron una clase con uno de los responsables de la cocina y comedor de la propia universidad, que les explicó los aspectos que debían tener en consideración: planes de control (manipulación de alimentos, plagas, aguas, abastecimientos, etc.); buenas prácticas en la manipulación de alimentos y en el proceso de cocinado; trazabilidad; recepción de materias primas; recipientes en función de su uso; etc. Para terminar, los alumnos visitaron la cocina viendo de forma práctica lo que se les había explicado en el aula.

Relacionado con la alimentación se prestó especial atención a lo concerniente con alergias alimentarias, diabetes e intolerancias, ya que el cuidado en la preparación y manipulación de los alimentos, almacenaje y composición es de vital importancia.

La distribución de espacios, mobiliario, distribución del mismo y objetos adquiridos pueden facilitar o dificultar la adquisición de la autonomía de los alumnos. Esto sucede en relación con la higiene y el aseo, el sueño, la alimentación y el vestido, por lo que cada decisión tomada debía tener siempre, además, este objetivo.

\section{Otros aspectos que se tuvieron en consideración}

Además de lo ya mencionado, toda la experiencia que se está presentando tiene como trasfondo dos conceptos interrelacionados: el mantenimiento de la salud y la prevención de enfermedades y accidentes.

Para el mantenimiento de la salud y la prevención de enfermedades la limpieza es, quizás, lo más importante. Por ello, cada equipo docente tuvo que buscar información sobre cómo limpiar los diferentes espacios (productos, usos, precauciones...) y uno de los aspectos a tener en cuenta a la hora de proponer una adquisición de material o mobiliario fue que se limpiara fácilmente.

Se analizó también la mejor forma de actuar ante una emergencia y se tuvo en 
consideración la ubicación de las aulas ante una posible evacuación (por ejemplo, los bebés y los niños más pequeños deben ser los que tengan el aula ubicada más cerca de la salida). Una emergencia puede ser también la aparición de alguna sintomatología que nos indique que un alumno está enfermo: fiebre elevada, tos, exantemas, dolor de cabeza... Saber cómo actuar y, en su caso, hacer una aproximación a lo que sucede para poder tomar medidas preventivas es algo que debe saber todo profesor.

Aunque en la actualidad no es necesaria la existencia de una enfermería ni la presencia de personal sanitario permanente, cada escuela sí debe tener un espacio en el que poder atender estas emergencias, con un botiquín adecuado y formación para el personal de la escuela, para que puedan usarlo en los casos en los que así pueda hacerlo un profesor. En este sentido, se dieron nociones básicas de primeros auxilios y de uso y reposición de los elementos del botiquín, así como las diferentes formas de contactar con servicios de emergencias.

En cuanto a la prevención de accidentes, se trató específicamente las condiciones que debe tener un aula y patio seguros, así como la seguridad en otros espacios del centro educativo.

En la actualidad no existen dudas sobre la necesaria colaboración entre la familia y la escuela y en un proyecto de estas características no podía faltar. Con este fin los alumnos tuvieron que preparar distintos materiales:

خ Planificación de una sesión de inicio de curso en el que se explique a los padres cómo se va a llevar a cabo el control de esfínteres en el aula para solicitar su colaboración en el hogar.

入 Cómo hacer una sesión formativa con las familias sobre la seguridad en el hogar.

7 Redacción de notas dirigidas a los padres contemplando diversas eventualidades: alumno que enferma, existencia de alergias, intolerancias u otras enfermedades...
7 Autorizaciones preceptivas para algunas acciones que deben hacer los docentes: dar medicación, salir de excursión...

入 Notas para que los padres traigan materiales al colegio: ropa, pañales, objetos de aseo...

7 Bienvenida al nuevo año académico y despedida de curso.

\section{Y finalizamos...}

Como se ha mencionado al principio de este artículo, la asignatura de Autonomía Personal y Salud Infantil finalizaba con la realización de una maqueta a tamaño 1:50 de cada una de las escuelas infantiles, que debía basarse en los planos definitivos de cada centro educativo.

Este último reto resultó bastante complejo, ya que los estudiantes carecían de conocimientos básicos para hacerla, lo cual supuso dificultades técnicas como: selección de materiales y su uso en una maqueta, escalado (lo más problemático), representación del mobiliario y los espacios, etc. Finalmente, todos los equipos docentes presentaron su maqueta en la que quedó de manifiesto lo que querían hacer.

El último día de la asignatura se Ilevaron las maquetas a la clase y se comentaron, destacando lo que estaba bien y podría ser factible y aquello que hubiera sido inadmisible en un proyecto emprendedor real (espacios excesivamente pequeños, espacios diáfanos desproporcionados, aulas en las que solo cabían mesas y sillas sin espacio para moverse en otro tipo de actividades menos estructuradas, etc.).

\section{Problemas y mejoras en el proyecto}

Quizás el mayor problema ha sido que los alumnos están en su primer curso del grado y en el primer cuatrimestre, con lo que aún no han empezado su formación como futuros profesores. Esto hace que gran parte de las decisiones que se tomaron en los grupos de trabajo no estuvieran tan fundamentadas en criterios pedagógicos como hubiera sido deseable. Esta 
situación se intentó paliar con el seguimiento de los trabajos, el asesoramiento y la revisión.

Un segundo problema a destacar es el referido a la dinámica de trabajo de los grupos. Pese a que se indicó a los alumnos que, como si fuera una situación real, aquellas personas que no trabajaran adecuadamente en el grupo debían ser expulsadas (despedidas si fuera un proyecto en funcionamiento), ninguno de los dos equipos en los que hubo problemas se atrevieron a hacerlo. Es necesario, en este sentido, ahondar en la idea de que si los demás hacen el trabajo por los que no participan, estos no solo abusan de sus compañeros, sino que, además, están haciendo un aprendizaje negativo: "no trabajes, que alguien lo hará por ti".

Algo que resultó muy llamativo fue la distribución excesivamente tradicional de los espacios. Las aulas, en la mayoría de los casos, estaban pensadas con pupitres para casi la mayoría de los grupos de edad y con un margen de trabajo fuera de la mesa muy limitado e, incluso, imposible de realizar. Es posible que los alumnos estén reflejando su propia experiencia como estudiantes y que, dado que acaban de comenzar su formación como futuros profesores, aún no puedan realizarlo de otra forma. En próximos cursos se intentará paliar mediante imágenes de espacios más versátiles y vídeos de actividades en aulas muy diversas.

Finalmente, y relacionado con el punto anterior, es de destacar la poca creatividad mostrada por los alumnos, que dis-

\section{HEMOS HABLADO DE}

\section{Educación Infantil; emprendimiento educativo; salud; autonomía personal; prevención; prevención de accidentes; equipación de aulas.}

Este artículo fue solicitado por PADRES Y MAESTROS en marzo de 2018, revisado y aceptado en junio de 2018.

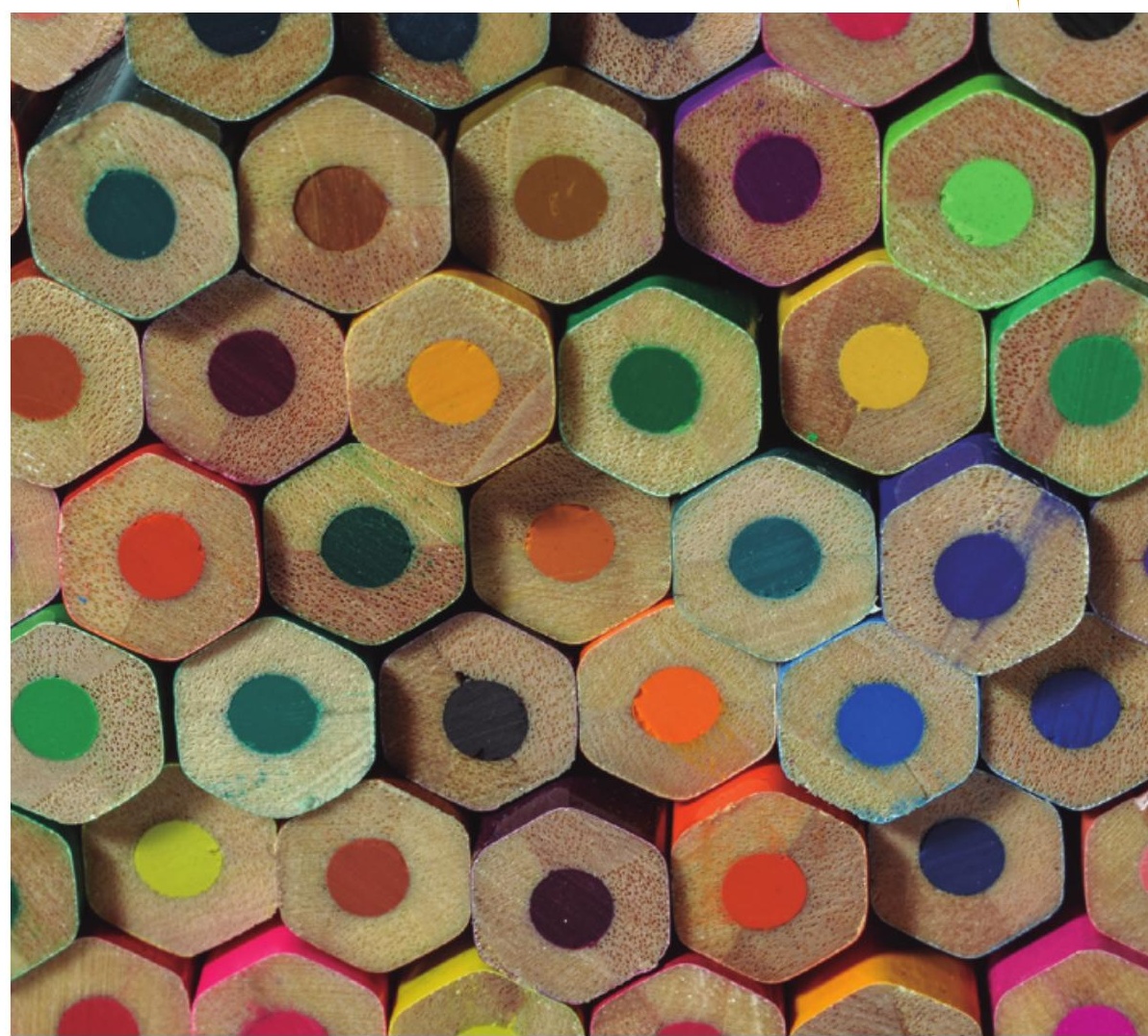

ponían de libertad absoluta en algunos aspectos de su trabajo y que optaron por distribuciones cuadradas o rectangulares, mesas y sillas o librerías, sin otro tipo de mobiliario que fomentara la creatividad de los niños y sin "arriesgar" en espacios más versátiles, compartidos, multiusos...

\section{(D.) DARA SABER MÁS}

Área de Coordinación Territorial. (2010). Protocolo de condiciones técnico-sanitarias para la instalación de los centros de cuidado y recreo infantil y escuelas infantiles. Recuperado de http://www. madrid.es/UnidadWeb/UGNormativas/Normativa/2010/ficheros/ ProtocoloEscuelalnfantil.pdf

Comunidad de MADRID (ed.). (s. f.). Quiero montar... una escuela infantil (Cuadernos de Orientación para el emprendimiento). Recuperado de goo.gl/kYD7sF

Decreto 18/2008, de 6 de marzo, del Consejo de Gobierno, por el que se establecen los requisitos mínimos de los centros que imparten primer ciclo de Educación Infantil en el ámbito de la Comunidad de Madrid. Vicepresidencia, Consejería de Presidencia y Portavocía del Gobierno Comunidad de Madrid. Recuperado de http:// www.madrid.org/wleg_pub/secure/normativas/contenidoNormativa.jsf?opcion $=$ VerHtml\&nmnorma $=4924 \&$ cdestado=P\#noback-button 